\title{
NASA moves to speed up grants process
}

[WASHINGTON] The US space agency NASA has begun to streamline its grants administration process after a review found widespread dissatisfaction among scientists who depend on the agency for research funding.

A series of reforms still awaiting final approval by top managers is intended to cut the lag between winning a grant and receiving funds to less than a month within two years. The wait for money at present is between 77 and 167 days, according to NASA.

A team led by Mary Kicza, associate director for space science programmes at the Goddard Space Flight Center in Maryland, began looking at problems with the management of grants last summer in response to complaints from the research community which caught the attention of Congress and the White House (see Nature 389, 218; 1997).

To understanding the scale of the problem and its possible solutions, Kicza's group sent letters to more than 6,000 scientists, consulted advisory groups, held open meetings, and met grant managers at other federal agencies.

Typical complaints from NASA-funded scientists included late payment, lack of predictability in the grants process, and burdensome paperwork. The solutions, to be fully implemented by 2000, would involve switching to more efficient electronic grants tracking, standardizing forms and deadlines for NASA Research Announcements (NRAs), and reducing the number of sign-offs needed

\section{South Africa gives green light to telescope}

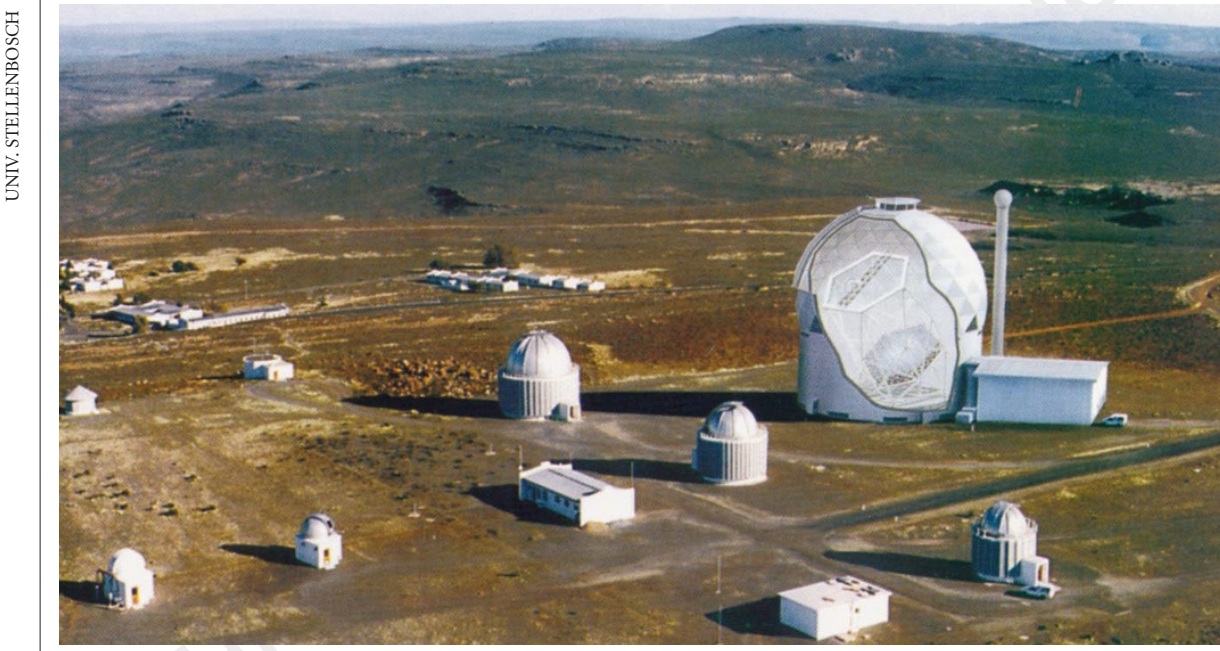

Building sight: artist's impression of SALT beside existing telescopes at Sutherland in South Africa.

[CAPE TOWN] Lionel Mtshali, South Africa's minister of Arts, Culture, Science and Technology, announced this week that the government is to foot half of the bill for the construction of the new Southern African Large Telescope (SALT).

The nine-metre instrument for optical and infrared astronomy will be the largest single optical telescope in the Southern Hemisphere. The government will contribute 50 million rand (US\$10 million) towards the cost, its largest investment so far in a single scientific project.

"South Africa is sending a strong signal to the world that we are prepared to support fundamental science at an international level," says Khotso Mokhele, president of the Foundation for Research Development, the research council under whose aegis the observatory falls.

The telescope, to be erected at the existing Sutherland site of the Southern African Astronomical Observatory (SAAO) in the Northern Cape Province, will complement the Hobby-Eberly Telescope at the McDonald Observatory in Texas (see Nature 384, 13; 1996).

The balance of the costs may be met by foreign sources in exchange for observing time. "South Africa cannot go it alone in a project of this magnitude," says Bob Stobie, SAAO director and chief architect of the project, who says he is "naturally delighted" with the government support.

Patricia Whitelock of SAAO says SALT's location and excellent viewing conditions will help studies in four areas: the early Universe and galaxy formation; galaxy populations; planetary searches; and quasars and active galactic nuclei.

A feasibility study has shown that South African industry can complete about half of the project's construction requirements. Technology transfer with US companies could have spin-offs for related areas of South African industry. Michael Cherry for grant solicitation and approval.

Even before the plan is fully in place, the agency has started reducing the number of signatures required for some steps in the process, Kicza says. Extra staff have been brought in to help work through the backlog.

Switching to electronic grants processing will also speed things up, but will be introduced more slowly as part of an agency-wide overhaul of accounting practices called the Integrated Financial Management Project.

The proposed goals are ambitious. The lag from grant selection to award of funds is targeted to drop to 62 days by the end of this year, to 46 days in 1999, and finally to 28 days in 2000. The agency hopes to shorten the interval between releasing an NRA and selecting winners from 285 to 240 days.

It hopes eventually to process annual grant renewals in only 16 days, down from the current 79 to 95 days. Principal investigators whose funding requests change by 20 per cent or less from one year to the next will not be asked to file new proposals. Grant applicants will also be able to track the progress of their proposals via the Internet.

Duplicative paperwork and too many people in the approval queue cause most delays, according to the Kicza team, which advocates a mostly paperless process. Grant information now is keyed in several times into separate and mutually incompatible databases, but the goal is to key it in once to an integrated electronic accounting system.

The reaction from space scientists is very positive, says Kicza. David Black, director of the Lunar and Planetary Institute in Houston, who heads a separate review of NASA research grants, says: "It's a tough goal [NASA] has set for themselves, but I think the only way you're going to really make the system respond is to push real hard."

David Burrows, a Pennsylvania State University astronomer and one of several scientists asked to review the new grants procedures, agrees that the targets are ambitious. But he says: "I think they can do it if they put their mind to it" and if they have support from top NASA managers.

But one temporary block is staffing within the agency's Office of Space Science. Last week the outgoing director of the its research programme, Henry Brinton, sent a plaintive letter to the space science community encouraging applicants for two positions that have remained unfilled for weeks. The posts are for 'discipline scientists' and include administering NRAs.

"The Office of Space Science is disappointed at the lack of positive response from the scientific community," wrote Brinton in his letter. As a result, "it is increasingly likely that both grants programs will suffer significant delays".

Tony Reichhardt 